\title{
A Review On Cognitive Mismatch Between Computer and Information Technology And Physicians
}

\author{
Fozia Anwar \\ CIS Department \\ Universiti Teknologi Petronas \\ Perak, Malaysia
}

\author{
Dr. Suziah Sulaiman \\ CIS Department \\ Universiti Teknologi Petronas \\ Perak, Malaysia
}

\author{
Dr. P.D.D.Dominic \\ CIS Department \\ Universiti Teknologi Petronas \\ Perak, Malaysia
}

\begin{abstract}
Health Information Technology has a great potential to transform the existing health care systems by making them safe, effective and efficient. Multi-functionality and interoperability of health information systems are very important functions. Hence these features cannot be achieved without addressing the knowledge and skills of the health care personnel. There is a great mismatch between Information Technology knowledge and skills of physicians as this discipline is completely missing in their educational tenure. So usability of health information technologies and system as well as evidence based practice in the future can be improved by addressing this cognitive mismatch. This will result in persistent partnership in HIS design between physician and IT personnel to get maximum usibility of the systems,
\end{abstract}

Keywords- cognitive mismatch; HIT; usibility.

\section{INTRODUCTION}

Information technology in health sector is spreading globally [1]. There are major campaigns in many countries which are involved not only large expenditures but public resources as well to boost the use and adoption rate of health information systems (HIS) and technologies. Therefore for the successful usability of HIS it is critical to address physician's views and skills on the use of these technologies [2].

Use of health information technology is offering evidencebased practice to endorse health and human prosperity. Health information technology (HIT) consists of a set of technologies with a great diversion for transmitting and managing health care data for the use of all stakeholders of health care systems [3]. Therefore the development of user-centered information systems is important to get best usability and advantages of the developed systems. Development of the user centered information system is like a pendulum that has to be swung between users and developer. The success of the ICT system depends on the balance of the pendulum in the form of input and feedback from the both ends. In most of the cases of the HIS the balance of the pendulum is disturbed due to lack of information technology cognitive skills of physicians. Hence the usability of the particular healthcare information system could not be achieved at the extent of the expectations [4].

Health care software developers often neglect significant characteristics, tasks, user preferences, knowledge skills and usability issues from the physician point of view resulting in systems that decreases productivity or simply remain unusable for the end-users [4]. Users of healthcare information system are dynamic and hence their needs are, so, development of any solution, system, or technology should be accounted the needs and requirements of the end users [6] [7] [8].

Definition of the term Cognitive skills varies but American Psychological Association's (2007) define as "all forms of knowing and awareness, such as perceiving, conceiving, remembering, reasoning, judging, imagining and problem solving."'[9] Simple definition of cognitive skills could be that these are the skills that one has learnt and ability to learn further new knowledge. Cognitive skills and cognitive ability of people had a profound effect in making a successful adoption and implementation of an information system with great usability.

The information technologies have greatly influenced on medical research, education, and healthcare delivery [10]. Therefore, medical schools should fit into place specialists to educate both students and tutors simultaneously; hence it is necessary to make additions and alterations in medical education accordingly [11].

\section{LITERATURE REVIEW}

\section{A. Role of Health Informatics}

A great philosopher Immanuel Kant said: "We see things not as they are but as we are". Perception and interpretation are having the same meaning. Anxiety of present situation having past experience is the perception. Both terms processing and perception are frequently used interchangeably. The etiology of misinterpretation is lack of experience or knowledge about the information technology.

Information plays a crucial role in medicine. All the time physicians are playing with the information they create, collect, search, adapt; in fact they drown in information. Medical or health informatics is all about this. The exact position of medical informatics is at the intersection of information technology, cognitive science, artificial intelligence, and medicine. So this is not a simple field involving only one aspect like medical computing, telecommunications, or information engineering, rather it is a dialogue between 
physicians, patients, and medical informaticians in a medical information system. Rather it explores and develops new knowledge, builds new theories, and organizes principles and solutions. Today's challenge is not to have an access of hardware rather it is the ability to use the information system. HIT technologies and information systems develop the way to positively increase the outcome of clinical care. Computers and evidence decision makings are two pillars of health informatics. To take full advantage of the HIT we have to learn the skills for framing and analyzing and integrating the healthcare information [12].

It is needed that end-users especially physicians should participate in healthcare IT development process [13]. Different models are suggested for better collaboration between users and IT experts. Parmit K Chilana suggested a model which emphasizes the persistent partnership of healthcare domain experts and IT experts throughout the development, implementation, evaluation and deployment processes. It gives emphasis on improving interdisciplinary skills on both ends of the pendulum to achieve a good balance. As a result of which an ICT system can be made which is not only be able to support the goals of the complex domain but can clearly outline the challenges of clinical ICT system [14].

It is essential in the research field of health informatics that a good fit and faith must persist in an ICT system and clinical practices [13]. Nevertheless, few numbers of studies have been done to answer the question of the cognitive aspects and need of interdisciplinary skills of the users and IT experts of different domains and the impact of the trainings given to users of HIS. Terms HIT and HIS are used in the research literature to cover a wide range of information technology applications in health care.

Trend of IT applications use is increasing by the Health Professionals (physicians, nurses and allied Staff), as, some health professional also develops, deploy or research health care IT [15]. Consequently, Health Professionals need to educate themselves for their respective roles along with their temporal requirements in health informatics [16] as their cognitive skills about IT and IS are not addressed throughout their educational tenure. Some examples of IT use in healthcare sector are use of physician digital assistance (PDA's), computerized physician order entry (CPOE), electronic health record (EHR), clinical decision support system (CDSS), picture archiving and communication system (PACS), radiology information system (RIS), pharmacology information system (PIS), hospital information system (HIS), disease early warning system (DEW), Telemedicine and health management information system (HMIS) [18].

Shah and Robinson found some key impediments to user involvement in HIT which are lack of resources, attitudes of technical developers and healthcare personnel, and lack of understanding the appropriate interdisciplinary knowledge and skills. However, a physician's involvement is very crucial for the success of HIT [19]. A proactive use of information technology in the health sector empowers consumers of health services to have an easy access health information and decision making tool and by the employment of HIT. Health professionals can collaborate more easily when distance is a major factor in health care delivery [20]. In past HIT applications were used for administrative activities and financial activities rather assisting and delivering health care [21].

Majumder identifies different trends in medical education. There is a noticeable change in healthcare environment due to advancement of ICT and the pervasion of World Wide Web in medicine. The health sector is investing a lot in the information systems and health technologies, so, physician have to depend on ICT and informatics skills for providing their contributions in research, education and health care organization. Therefore, knowledge and skill to use ICT application for self-directed learning is important for medical professionals. Some international organizations like the World Bank and WHO have taken initiatives to orient interdisciplinary skills in the health sector to prepare physicians to cope with the ever changing dynamic health environment. Such pedagogical environments require a lot of cognitive skills and interdisciplinary knowledge [22].

By addressing the IT knowledge cognitive barrier medical students not only be better exposed to evidence based decision making but it will foster their capacity towards a new world of learning. By exposing medical professionals to the information technology knowledge will prepare them for a better orientation of electronic health information systems. Koschmann assessed three different approaches to address cognitive mismatch, which are learning about, through and with computers. He concluded that none of the above mentioned approaches are sufficient alone in fact combination is required [23].

HMSO Report showed that the failure of The National Program for IT in the NHS is the lack of IT skills within National Health Services [24]. Still culture of use of IT in the health care system is not established yet. Bond, 2006 in his doctoral dissertation explored the ways of developing informatics skill and knowledge to fill the knowledge gap .He used a questionnaire tool to collect data from 132 nurses about their usability experience and practicing IT skills behavior in their routine practices [25].

In another study Steven R. Simon and Rainu Kaushal randomly took 1884 physicians as their sample size with the response rate of $71.4 \%$. They explored the level of physicians' use of electronic health record among two groups and also investigated the factors which correlate this use. One group is that which used EHR's functions and thought that they are a useful tool for their practice. The other group is low users of the information system and they even don't aware of the total available and useful functionalities of the system. Therefore the adoption of HIT and HIS is very critical and is a key issue in the health care system. In the past more attention was given on adoption but little literature is available on physician's capabilities to use the system [26].

On CDCP (the Centers for Disease Control and Prevention) panel a report named "Electronic Medical Record/Electronic Health Record Systems of Office-based Physicians: United States" states that physicians are not using the core functionalities of electronic health record because of two possible reasons. One is that their system may lack in having 
these functionalities or the other possibility is that the physician may not aware or have not had knowledge of the presence of those functionalities in their system. When it is analyzed that what is the reason that physicians don't know about the availability of the system results the largest gap in the knowledge and cognition mismatch was there [27]. Adherence to data definitions with the proper involvement of end users in the development process of HIS are important factors in gaining the interoperability of the system [28].

\section{B. Knowledge And Skills Of Health Professionals}

The health care system is an information intensive domain in which timely access to quality information with accuracy is very critical. Medical professionals are one of the major stakeholders of health information technology. There are lots of barriers to acceptance of information technology by this group of stakeholders. Barriers of this knowledge gap are sociological, cultural, and organizational and technological.

Some researchers reported that physicians are reluctant to introduce the systems into their practice because of time constraints [29] [30] [31]. At present healthcare professionals still seem to be lagging behind in participation in IT Development [32]. One important factor is knowledge and cognitive barrier as their level of information technology literacy is low to use applications of IT [33]. This low level even indefensibly low level of IT literacy or basic knowledge and skills is the reason argued by the health professionals. Due to this reason understanding the concepts and importance of health information systems and information technology cannot be justified by medical professionals. Nykanen and Karimaa in their research stated that the starting point for development of health information system should be to acquire an insight into the healthcare domain where the information system is going to be used [34].

\section{Adoption And Use Of Hit}

Health information technology (HIT) is a vital element which can address inefficiencies and discrepancies in healthcare in an efficient way. So it is necessary to understand the challenges hurdles and barriers which can limit meaningful use of HIT. Poorly developed user interface and system design is a big hurdle in the clinical workflow and can result in wasted time, poor data collection, misleading data analysis, and potentially negative clinical outcomes. Decisions on technology acquisitions and implementations are often made by individuals or groups that lack clinical informatics expertise [35]. Hence it results in poor usability of the system. Developing such a system is a waste of human resources as well as economics. Proper introductory education of IT is one of the key antecedents of attitude toward computer use behavior by humans [36].

A "design-reality gap" concept is introduced by Heeks arguing the misunderstandings and mismatches between the current realities and design of healthcare information systems [37]

\section{CONCLUSION}

Information technology cognitive skills for physicians are very critical to address in gaining persistent partnership of physicians in the HIT Application development and in achieving the maximum usability of health information systems and technologies. It will be very helpful in successful implementation of HIS but also foster the evidence based practice and increase usability of HIS. Interdisciplinary skills in medical education will be of great value in future research as well.

\section{REFERENCES}

[1] Fozia Anwar, Azra Shamim" Barriers in Adoption of Health Information Technology in Developing Societies" International Journal of Advanced Computer Science and Applications.Vol 2 Issue 8 August 2011

[2] Norm Archer, Mihail Cocosila, A Comparison of Physician PreAdoption and Adoption Views on Electronic Health Records in Canadian Medical Practices, J Med Internet Res. 2011 Jul-Sep; 13(3): e57

[3] Viitanen J, Hyppönen H, Lääveri T, Vänskä J, Reponen J, Winblad I. National questionnaire study on clinical ICT systems proofs: physicians suffer from poor usability. Int J Med Inform. 2011 Oct;80(10):708-25.

[4] Marc Berg, Patients and professionals in the information society: what might keep us awake in 2013, International Journal of Medical Informatics 66 (2002) 31_37.

[5] Susanna Martikainen, Johanna Viitanen, Mikko Korpela, Tinja Lääveri. Physicians' experiences of participation in healthcare IT development in Finland: Willing but not able. International Journal of Medical Informatics 81 (2 0 12) 98-113 Häyrinen, K., Saranto, K., Nykänen, P. (2008) Definition, Structure, Content, Use and Impacts of Electronic Health Records: A Review of the Research Literature. International Journal of Medical Informatics 77, 291-304.

[6] J. Bardram, A. Mihailidis, W. Dadong (Eds.), Pervasive Computing in Healthcare, CRC Press, Taylor \& Francis Group, USA (2006)

[7] R. Lenz, T. Elstner, H. Siegele, K.A. Kuhn A practical approach to process support in health information systemsJ. Am. Med. Inform. Assoc., 9 (6) (2002), pp. 571-585

[8] American Psychological Association. 2007. APA Dictionary of Psychology. Washington, D.C.:American Psychological Association.

[9] Masys DR. Advances in information technology. Implications for medical education. West J Med. 1998; 168: 341 -347.

[10] Ward JPT, Gordon J, Field MJ, Lehmann HP. Communication and information technology in medical education. Lancet. 2001; 357: $792-$ 796.

[11] Paperny DM. Computers and information technology: implications for the 21 st century. Adolesc Med. 2000; 11: 183- 202.

[12] Pauker SG, Stahl JE. Medical informatics: where the action is [editorial].West J Med 1997 Feb; 166:148-150

[13] Reuss, E., Rochus, K., Naef, R., Hunziker, S., Furler, L. (2007a) Nurses' Working Practices: What can We Learn from Designing Computerized Patient Record Systems. In A. Holzinger (eds.) USAB2007, Graz, Austria, Springer-Verlag, Berlin, Heidelberg, 55-68.

[14] Parmit K. Chilana, Andrew J. Ko, Jacob O. Wobbrock, Tovi Grossman, George Fitzmaurice. Post-Deployment Usability: A Survey of Current Practices, CHI 2011

[15] Sebastian Garde, David Harrison, Evelyn Hovenga Australian Skill Needs Analysis of Health Informatics Professionals Volume 1: Rationale \& Methods, Key Findings \& Conclusions, Research Report 1/2005

[16] Shah, S. G. S., Robinson, I. (2007) Benefits of and Barriers to involving Users in Medical Device Technology Development and Evaluation. International Journal of Technology Assessment in Health Care 23, 131137.

[17] Viitanen J, Hyppönen H, Lääveri T, Vänskä J, Reponen J, Winblad I. National questionnaire study on clinical ICT systems proofs: physicians suffer from poor usability. Int J Med Inform. 2011 Oct; 80(10):708-25. 
[18] Innovators and Visionaries: Strategies for Creating a Person-centered Health System. FACCT: Foundation for Accountability; September 2003.

[19] Shah, S. G. S., Robinson, I. (2006) User Involvement in Healthcare Technology Development and Assessment: Structured Literature Review. International Journal of Health Care Quality Assurance 19, 500515.

[20] Innovation of health technology, Report by Centre of AHIP center of policy and research, Effective new solution for Americans health insurance plans

[21] Audet AM, Doty MM, Peugh J, Shamasdin J, Zapert K, Schoenbaum S, Information Technologies: when will they make it into physicians' black bags? MedGenMed. 2004; 6:2. [PMID: 15775829](13)

[22] Majumder A, D'Souza U, Rahman S. Trends in medical education: Challenges and directions for need-based reforms of medical training in South-East Asia. Indian J Med Sci 2004; 58:369-80

[23] Koschmann T. Medical education and computer literacy: learning about, through, and with computers. Acad Med. 1995 Sep; 70(9):818-21

[24] Guest Editorial Nurses' requirements for information technology: A challenge for educators International Journal of Nursing Studies 44 (2007) 1075-1078.

[25] National Audit Office, 2006. Department of Health. The National Program for IT in the NHS.

[26] Steven R. Simon; Rainu Kaushal; Paul D. Cleary; Chelsea A. Jenter; Lynn A. Volk; E. John Orav; Elisabeth Burdick; Eric G. Poon; David W. Bates. Physicians and Electronic Health Records: A Statewide Survey Arch Intern Med. 2007; 167(5):507-512.

[27] http://www.cdc.gov/nchs/products/pubs/pubd/hestats/electronic/electroni c.htm. Accessed on February 6, 2012.

[28] Khadzir bin Sheikh Haji Ahmad, Health Data Integration, Malaysian Journal of Public Health Medicine, Vol. 11(Suppl 1) 2011

[29] Anogianakis, G., S. Maglavera, and A. Pomportsis, ATTRACT-applications in telemedicine taking rapid advantage of cable television network evolution. Studies in Health Technology \& Informatics, 1998 50: p. 60-6.

[30] Bielli, E., A Wireless Health Outcomes Monitoring System (WHOMS): development and field testing with cancer patients using mobile phones. BMC Medical Informatics \& Decision Making, 2004. 4: p. 7.

[31] Muuronen, A. (2008) Lääkäreillä on liikaa paperitöitä (in Finnish). (The doctors have to do too much paper work). Helsingin Sanomat newspaper, an article published in discussion column,published in December 6th, 2008.

[32] S. De Rouck, A. Jacobs, M. Leys A methodology for shifting the focus of e-Health support design onto user needs: a case in the homecare field Int. J. Med. Inform., 77 (9) (2008), pp. 589-601

[33] David A. Dzewaltowski, Paul A. Estabrooks, Lisa M. Klesges, Sheana Bull and Russell E. Glasgow . Behavior change intervention research in community settings: how generalizable are the results? Health Promotion International Oxford Journal, Volume19, Issue2 Pp. 235-245.

[34] P. Nykanen, E. Karimaa, Success and failure factors in the regional health information system design process-result from a constructive evaluation study, Methods Inf. Med. 4 (2006) 85-89

[35] Kadry, Bassama; Sanderson, Iain Ca; Macario, Alexb, Challenges that limit meaningful use of health information technology, Current Opinion in Anaesthesiology: April 2010 - Volume 23 - Issue 2 - p 184-192

[36] Chuang, Y.H., Chuang, Y.W., 2002. "Attitudes of two-year RNBSN nursing students towards computers", The Journal of Health Science 5 (1), 71-84

[37] R. Heeks, Health information systems: failure success and improvisation, Int. J. Med. Inform. 75 (2006) 125-137

\section{AUTHOR'S PROFILE}

Fozia Anwar is a research scholar in CIS department of University Technology Petronas and after completing her Bachelor degree in dentistry she did MS in Health Informatics from COMSATS Institute of Information and Technology. 